\title{
Vascular markers CD31, CD34, actin, VEGFB, and VEGFR2, are prognostic markers for malignant development in benign endometrial polyps
}

\author{
Bodil Hvingel ${ }^{1}$, Marit Lieng ${ }^{2}$, Borghild Roald ${ }^{3}$, Anne Ørbo ${ }^{4}$ \\ ${ }^{1}$ Department of Gynecologic Oncology, Clinic for Surgery, Cancer and Women's Disease, University Hospital of Tromsø, Tromsø, \\ Norway \\ ${ }^{2}$ Department of Gynecology and Obstetrics, Oslo University Hospital, Oslo, Norway \\ ${ }^{3}$ Department of Pathology, Oslo University Hospital, Oslo, Norway \\ ${ }^{4}$ Department of Clinical Pathology, University Hospital of Tromsø, Tromsø, Norway \\ Email: bodil.hvingel@unn.no, Marit.Lieng@,oslo-universitetssykehus.no, borghild.roald@uus.no, anne.orbo@uit.no
}

Received 17 November 2011; revised 15 December 2011; accepted 31 December 2011

\section{ABSTRACT}

Intention of the study: The prevalence of endometrial polyps has been demonstrated in between $10 \%$ and $35 \%$ of all women, but knowledge regarding malignant potential within polyps is limited. Even though premalignant and malignant changes have been reported in up to $24 \%$ of all cases, no objective tissue markers have ever been developed for routine diagnostics to select high risk cases. As vascular changes and activation of endometrial angiogenesis has been demonstrated in former studies, our main objective was to evaluate different members of the angiogenic pathway as potential risk factors for cancer development. Patients and methods: Formalin-fixed, paraffin-embedded tissue from 15 women with benign endometrial polyps, and 16 women diagnosed with endometrial cancer were included. Immunohistochemical investigation with antibodies against VEGF, VEGF-B, VEGFR2, VEGFR3, CD31, CD34, actin, and factorVIII was performed, followed by evaluation of staining intensity of microvessels, evaluation of $\mathbf{H}$-score in glands (cell membrane, cytoplasm) and stroma, and measurement of micro vessel density. Results: Expression of CD31 in microvessels was significantly stronger in cancers compared to endometrial polyps $(P=0.006$ for arterioles, $P=\mathbf{0 . 0 3 8}$, for venyles, and $P=\mathbf{0 . 0 0 2}$ for capillaries, respectively), whereas, a reverse change was shown for CD34. Expression of actin in capillary walls was also significantly increased in cancers compared to polyps $(P=\mathbf{0 . 0 0 2})$. No significant difference was found for staining intensity in microvessels (arterioles, venyles or capillaries) in endometrial benign polyps compared with endometrial cancers for VEGF, VEGFB, VEGFR2, VEGFR3, or Factor VIII. Also no difference in $\mathrm{H}$-score values between benign polyps and endometrial cancers could be detected in glandular epithelium, in epithelial cell membrane or in stroma for VEGFR3, CD31 or Factor VIII. Conclusions: The present study strongly indicates that activation of angiogenesis differs in benign endometrial polyps and endometrial cancers. Thus, immunohistochemical expression of specific angiogenic markers may be of great importance as prognostic factors in the routine diagnostics of this lesion. The ratio between stromal expression of CD34 and actin might be of particular interest to select polyps with increased malignant potential.

Keywords: Endometrial Polyps; Endometrial Cancer; Vascular Markers; Prognosis

\section{INTRODUCTION}

Although endometrial polyps are frequently occurring structures, routine diagnostic and routine therapy based on objective and profound knowledge of malignant potential is limited. The prevalence of endometrial polyps shows great differences in comparable studies varying between $10 \%$ in one population and up to $35 \%$ in others [1-6]. Polyps exceeding a certain size are easily visualized by transvaginal ultrasound, sonography or hysteroscopy, but the large variation in reported prevalence may reflect the difficulties in confirming the histological diagnosis. Thus, polyps removed by currettage are often fragmented and therefore overlooked or neglected by the pathologist.

Malignant transformation in endometrial polyps is known to occur in only a minority of all lesions and even if results from different studies may be discordant, most endometrial polyps are known to be benign lesions [1]. In one former study of polyps from women presenting 
with abnormal uterine bleeding $23.8 \%$ showed premalignant changes (complex and atypical hyperplasia) and $1.5 \%$ had endometrial cancer [1]. In another report $11.3 \%$ of the studied polyps had hyperplasia and $3.2 \%$ were malignant [7]. However, malignancy in endometrial polyps associated with tamoxifen use has been reported to be considerably more frequent $[3,8]$.

Thus, endometrial hyperplasia and endometrial polyps may be considered as risk factors for endometrial carcinoma and some evidence exist that polyps may be indicators of malignant transformation [9]. In histopathological evaluation of premalignant endometrial lesions it is widely accepted that development of endometrial carcinoma may occur through a spectre of hyperplastic lesions, varying from simple hyperplasia to complex atypical hyperplasia.

Although never proved, similar changes have been expected to occur in polyps. Malignant change in endometrial hyperplasia is reported to vary from $2 \%$ up to more than $50 \%$ in different materials [10-13]. Whether these criteria, which have been seriously criticized for low reproducibility, are predictive for malignant development within endometrial polyps has never been seriously confirmed.

So far, the knowledge regarding risk factors of malignant development in endometrial polyps is limited and no objective reliable clinical or biological markers exist for the prediction of progression to endometrial carcinoma. In the search for objective, prognostic markers in endometrial polyps Lieng and co-workers recently found that pulse wave Doppler assessment of downstream resistance in arterioles was significantly different in endometrial polyps compared to endometrial cancers [14]. In the endometrium from healthy, fertile women, expression of angiogenic markers like VEGF-A, -B, and -C, and VEGF receptors 1-3 in endometrial blood vessels indicate a highly structured involvement of angiogenesis [15].

Increasing levels of angiogenesis has been reported in endometrial hyperplasia and cancer compared to normal proliferative endometrium [16]. Previous studies of endometrial cancers additionally have demonstrated an association between prognosis and level of angiogenesis $[17,18]$. Thus, more exact diagnostics in daily routine for the selection of polyps with increased malignant potential would be essential. Against this background, we decided to investigate whether immunohistochemical expression of angiogenic markers were different in endometrial carcinoma compared to benign endometrial polyps.

\section{PATIENTS AND METHODS}

\subsection{Patients}

This prospective study included 15 consecutive women with benign endometrial polyps diagnosed by saline contrast sonohysterography (SCSH), and 16 consecutive women with endometrial cancer. The women with endometrial polyps were referred to the Department of Gynecology at Ullevaal University hospital following incidental sonographic findings suggestive of endometrial polyp. The women with endometrial carcinoma were referred after histologically verified malignancy in endometrial biopsy. The study protocol was approved by the local research ethics committee, and written and oral informed consent was obtained from all study participants.

\subsection{Immunohistochemistry}

Biopsies were routinely fixed in $4 \%$ buffered formaldehyde and embedded in paraffin before $5 \mu \mathrm{m}$ histological sections were made, stained with eosin and haematoxylin. Histological investigation of the routine specimens was performed by a gynaecologic pathologist (BR). Immunohistochemistry was performed according to customer's advice and the different procedures described in Tables 1 and 2 . The eight different investigated primary antibodies were against VEGF, VEGF-B, VEGFR2, VEGFR3, CD31, CD34, actin, and factor VIII.

Table 1. Procedures performed for the antibodies VEGF, VEGF-B, VEGFR-2 and VEGFR-3. Immunohistochemistry was performed according to customer's advice.

\begin{tabular}{|c|c|c|c|c|}
\hline Procedure/Antibody tested & VEGF & VEGFB & VEGFR2 & VEGFR3 \\
\hline \multirow{2}{*}{ Primary antibody } & Cat nr: RB-9031 & Cat nr: MAB751 & Cat nr: RB-9239-P1 & Cat nr: RB-9255-P \\
\hline & Rabbit polyclonal & Mouse monoclonal & Rabbit polyclonal & Rabbit polyclona \\
\hline $\begin{array}{l}\text { Negative control } \\
\text { Diluent only }\end{array}$ & $\begin{array}{l}\text { Multitissue titration } \\
\text { block }\end{array}$ & $\begin{array}{l}\text { Multitissue } \\
\text { titration block }\end{array}$ & $\begin{array}{l}\text { Multitissue } \\
\text { titration block }\end{array}$ & $\begin{array}{l}\text { Multi tissue } \\
\text { titration block }\end{array}$ \\
\hline Positive control & $\begin{array}{l}\text { Multitissue titration } \\
\text { block }\end{array}$ & $\begin{array}{l}\text { Multitissue } \\
\text { titration block }\end{array}$ & $\begin{array}{l}\text { Multitissue } \\
\text { titration block }\end{array}$ & $\begin{array}{l}\text { Multi tissue } \\
\text { titration block }\end{array}$ \\
\hline Company/purchaser & $\begin{array}{l}\text { Lab Vision, } \\
\text { California, USA }\end{array}$ & $\begin{array}{l}\text { R \& D Systems, } \\
\text { Minnesota, USA }\end{array}$ & $\begin{array}{l}\text { Lab Vision, } \\
\text { California, USA }\end{array}$ & $\begin{array}{l}\text { Lab Vision, } \\
\text { California, USA }\end{array}$ \\
\hline $\begin{array}{l}\text { Pre-treatment procedure } \\
\text { Staining }\end{array}$ & $\begin{array}{l}\text { Boil in TrisEDTA-buffer } \\
\text { standard Dako Autostainer }\end{array}$ & $\begin{array}{l}\text { Boil in TrisEDTA-buffer, } \\
\text { standard Dako Autostainer }\end{array}$ & $\begin{array}{l}\text { Boil in TrisEDTA-buffer, } \\
\text { standard Dako Auto-stainer }\end{array}$ & $\begin{array}{l}\text { Boil in TrisEDTA-buffer, } \\
\text { standard Dako Autostainer }\end{array}$ \\
\hline Titre & $1 / 150$ & $1 / 20$ & $1 / 100$ & $1 / 300$ \\
\hline
\end{tabular}


Table 2. Procedures performed for the antibodies CD31, CD34, actin and Factor VIII. Immunohistochemistry was performed according to customer's advice.

\begin{tabular}{|c|c|c|c|c|}
\hline Procedure/Antibody tested & CD31 & CD34 & Actin & Factor VIII \\
\hline Primary antibody & $\begin{array}{l}\text { Cat nr: } \mathrm{M} 0823 \\
\text { Mouse monoclonal }\end{array}$ & $\begin{array}{l}\text { Cat nr: } 790-2927 \\
\text { Mouse monoclonal }\end{array}$ & $\begin{array}{l}\text { Cat nr: } 760-2502 \\
\text { Mouse monoclonal }\end{array}$ & $\begin{array}{l}\text { Cat nr: } 760-2642 \\
\text { Rabbit polyclonal }\end{array}$ \\
\hline $\begin{array}{l}\text { Negative control } \\
\text { Diluent only }\end{array}$ & $\begin{array}{l}\text { Multitissue } \\
\text { titration block }\end{array}$ & $\begin{array}{l}\text { Multitissue } \\
\text { titration block }\end{array}$ & $\begin{array}{l}\text { Multitissue } \\
\text { titration block }\end{array}$ & $\begin{array}{l}\text { Multitissue } \\
\text { titration block }\end{array}$ \\
\hline Company/purchaser & $\begin{array}{l}\text { Dako Cytomation, } \\
\text { Denmark }\end{array}$ & $\begin{array}{l}\text { Ventana Medical } \\
\text { Systems, Arizona,US }\end{array}$ & $\begin{array}{l}\text { Ventana Medical } \\
\text { Systems, Arizona, US }\end{array}$ & $\begin{array}{l}\text { Ventana Medical } \\
\text { Systems, Arizona,US }\end{array}$ \\
\hline $\begin{array}{l}\text { Pre-treatment: } \\
\text { procedure Staining }\end{array}$ & $\begin{array}{l}\text { Boil inTRS ph } 6,1 \\
\text { Dako Autostainer }\end{array}$ & $\begin{array}{l}\text { Standard Ventana } \\
\text { program Ventana } \\
\text { Autostainer }\end{array}$ & $\begin{array}{l}\text { Standard Ventana } \\
\text { program Ventana } \\
\text { Autostainer }\end{array}$ & $\begin{array}{l}\text { Standard Ventana } \\
\text { program Ventana } \\
\text { Autostainer }\end{array}$ \\
\hline
\end{tabular}

\subsection{Evaluation of Immunohistochemical Expression in Epithelium, Epithelial Cell Membrane, and Stroma (H-Score)}

The results of immunostaining in epithelial tissue (epithelium in endometrial glands in polyps and malignant epithelium in cancers), epithelial cell membranes, epithelial cell cytoplasm and cytoplasm in stroma were examined semi-quantitatively by using an immunohistochemical histological score (H-score) which incorporates both the intensity and the distribution of specific staining. The $\mathrm{H}$-score has been previously formulated as

$$
\mathrm{HS}=\sum(\mathrm{Pi} \times \mathrm{i}) / 100,
$$

where Pi denotes the percentage of stained cells and $i$ denotes the intensity of the staining ranging from $1-3$ [19]. Epithelial tissue (epithelial cell membranes, epithelial cell cytoplasm) and cytoplasm in stroma were classified separately. A specific area within each specimen of polyps and carcinomas (hot spots) was defined for investigation by a gynecological pathologist (AØ). For each of the eight different antibodies used for immunohistochemical staining, this specific area was investigated for each case with reference to epithelium, cell membranes and stroma. Both staining intensity and number of positive cells were counted. Less than $10 \%$ positive cells were considered as negative and characterized as $0,10 \%$ - $30 \%$ positive cells were assessed as $1,31 \%-70 \%$ positive cells as 2 , and $71 \%-100 \%$ positive cells as 3 . In evaluating the staining intensity, a score of zero indicated an absence of staining. Scores of 1,2 and 3 indicated weak, moderate and strong immuno-reactivity, respectively. The H-score evaluation was performed visually as a consensus between a trained gynecologic pathologist (AO) and a PhD student (BH). Both investigators were blinded to the two patient groups. Internal protein control was performed regularly for each staining in cancers as well as in polyps.

\subsection{Evaluation of Immunohistochemical Staining Intensity in Microvessels}

A semi quantitative evaluation of staining intensity in microvessels: arterioles (vessels with defined muscular wall), capillaries (smallest vessels taking no more than a couple of erythrocytes), and venyles (larger diameter than capillaries lacking muscular wall) was performed by light microscopy as a consensus between a trained gynecologic pathologist (AO) and a PhD student (BH). Both investigators were blinded to the two patient groups. Light staining was evaluated as score $=1$, moderate staining as score $=2$ and strong staining as score $=3$. Finally, the intensity score values were compared for endometrial polyps and for cancers for each specific immunohistochemical antibody.

\subsection{Microvessel Density Measurement}

Microvessel density measurement was performed after CD 34 staining of the specimens. A modified Chalkley count method was utilized to measure microvessel density [20]. Within stroma of polyps and cancers, three areas of most intense neovascularization (vascular hotspots) were selected and marked for each specimen. Using the Q Prodit image analysing system (version 6.1; Leica, Cambridge, UK) with 30 micrometer grid lines the number of microvessels were counted within each separate hot-spots (magnification $40 \times$ ) and results were presented as mean of the three counts.

\subsection{Statistics}

Mann-Whitney two tailed unpaired test, GraphPad InStat version 3.06, GraphPad Software, San Diego California USA were employed for all statistical evaluations in the 
present study for comparison of patient groups using. P-levels $\leq 0.05$ were considered significant of the tree defined areas. Any stained endothelial cell or cell cluster separated from adjacent microvessel

\section{RESULTS}

\subsection{Patients}

The mean age of the patients with polyps was $58.0 \pm 8.1$ and for the cancer patients $63.1 \pm 10.3$. Body mass index for the patients with polyps and for the cancer patients was $27.5 \pm 5.8$ and $28.8 \pm 4.80 .5$, respectively. Endometrial thickness was described in $\mathrm{mm}$ as $15.1 \pm 8.2$ for the patients with polyps and $20.6 \pm 10.4$ for the cancer patients. Volume of polyp and tumour volume was estimated in $\left(\mathrm{cm}^{3}\right)$ to be $6.4 \pm 8.3$ and $10.9 \pm 6.9$ for polyps and cancers, respectively. Of all the included patients only five were premenopausal. Among the patients with

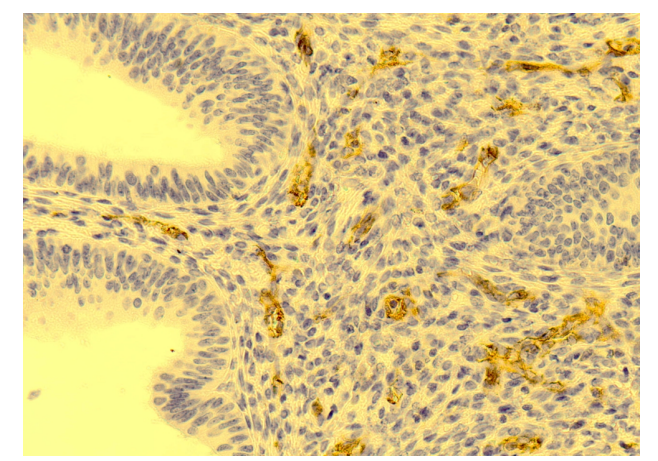

carcinomas, 14 were diagnosed as endometrioid carcinomas (all Figo stage 1 or Figo stage 2), one as seropapillary carcinoma (Figo stage 1), and one as clear-cell carcinoma (Figo stage 3 ). All the included polyps were diagnosed by the pathologist to be without atypia. All patients with cancers were treated according to the national routines.

\subsection{Results of Staining Intensity in Microvessels}

Evaluation of immunohistochemical expression demonstrated that expression of CD31 was significantly stronger in microvessels (arterioles, venyles, and capillaries) in cancers compared to endometrial polyps (Figure 1, and Table 3(a)). Reversely, for CD34, the intensity of immunohistochemical expression was reduced in cancers in all three types of microvessels compared to endometrial polyps; however, the reduction was significant only in venyles (Figure 2 and Table 3(b)). Also for actin the

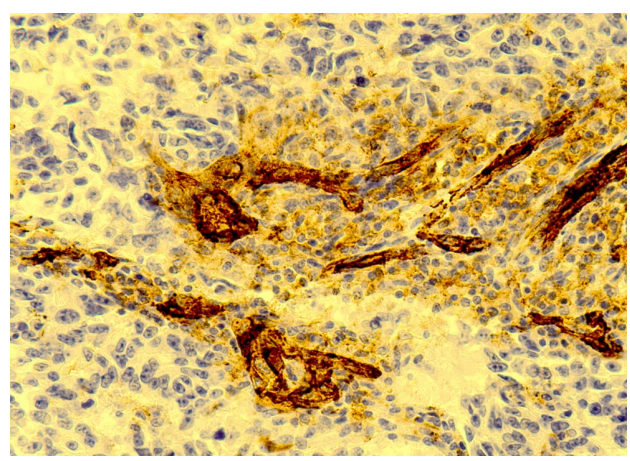

Figure 1. Left panel: The micro photo from an endometrial polyp shows expression of CD31 in microvessels (arterioles, venyles and capillaries) with endothelial cells staining light brown. The microvessels are surrounded by stromal cells which are negatively stained (blue). In the left part of the picture an endometrial gland is also demonstrated to be negative for CD31 (20× magnification). Right panel: The micro photo from endometrial cancer shows expression of CD31 in endothelium of microvessels (arterioles, venyles and capillaries) staining dark brown. The microvessels are surrounded by stromal cells which do express some CD31 showing light brown colour within cellular cytoplasm $(20 \times$ magnification).
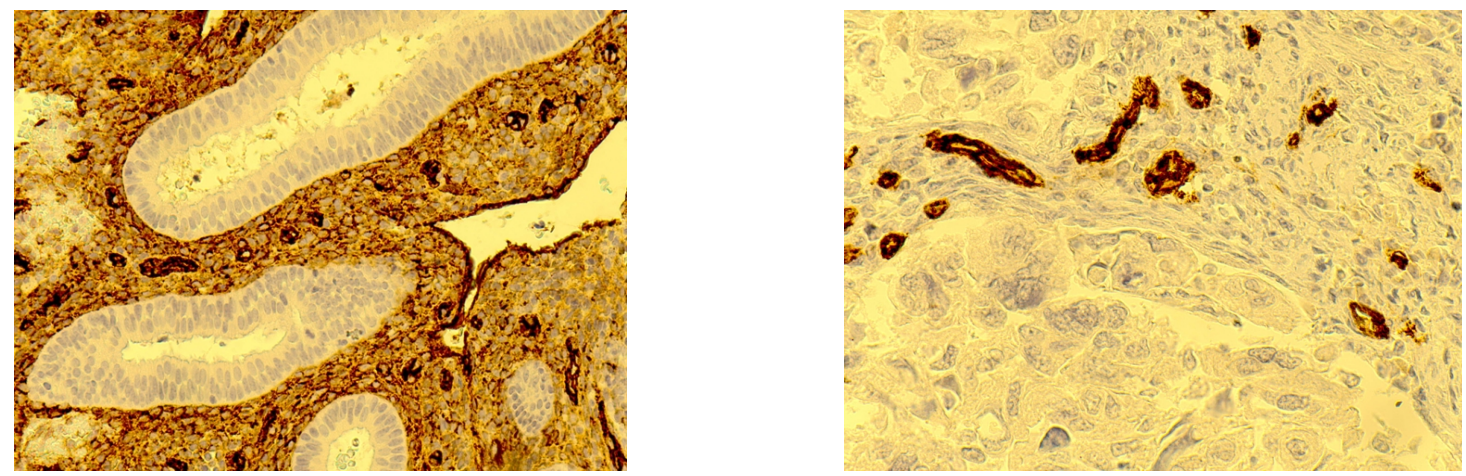

Figure 2. Left panel: The micro photo from an endometrial polyp stained with CD34 showing negatively stained glands surrounded by dark brown stromal cells expressing CD34. Dark brown stained microvessels are also localized within the stroma (40× magnification). Right panel: In contrast the micro photo of an endometrial cancer shows negatively stained stromal tissue with strongly positive microvessels (bridge of stromal tissue in the centre). Endometrial cancerous tissue surrounding stroma seen on both sides is also negatively stained (blue) $(20 \times$ magnification). 
staining intensity was increased in cancers compared to intensity observed in endometrial polyps, however, statistical difference was observed exclusively in capillaries (Figure 3 and Table 3(c)). No significant difference was found for staining intensity in microvessels (arterioles, venyles or capillaries) in endometrial benign polyps compared with and endometrial cancers for VEGF, VEGFB, VEGFR2, VEGFR3, or Factor VIII (data not shown).

\subsection{Results of $\mathbf{H}$-Score in Epithelium of Glands (Cytoplasm and Epithelial Cell Membrane) and Stroma (H-Score)}

VEGF was expressed with high H-score in cytoplasm of epithelial cells as well as in stroma in both polyps and cancers but no significant difference was found (Table 4(a)). For VEGFB a significant reduction in $\mathrm{H}$-score in epithelial cell membrane as well as in stroma was observed for cancers compared to endometrial polyps, whereas, in cytoplasm of the same cells no difference

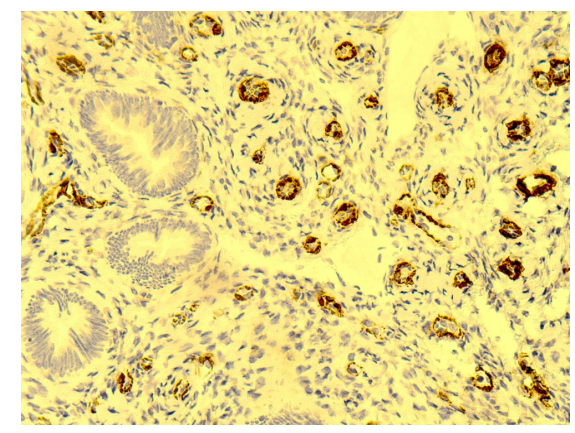

was detected (Table 4(b)). An increased H-score level in cytoplasm of glandular tissue in cancers was observed for VEGFR2 compared to polyps, but no difference in H-score in stromal tissue could be observed (Table 4(c)). $\mathrm{H}$-score values for CD34 in stroma was significantly reduced in cancers compared to endometrial polyps, whereas, stromal actin levels increased (Figures 2 and 3, Tables 4(d) and (e)). No difference in H-score values between benign polyps and endometrial cancers could be detected in glandular epithelium, in epithelial cell membrane or in stroma for VEGFR3, CD31 or Factor VIII.

\subsection{Result of Microvessel Density Measurements}

Image analyses of microvessel density in polyps and in cancers showed that the mean value of micro vessel density was $7.400( \pm 2.02)$ for polyps and $6.071( \pm 2.24$ for cancer, respectively. The results from the two groups were not significantly different $(\mathrm{P}=0.07)$.

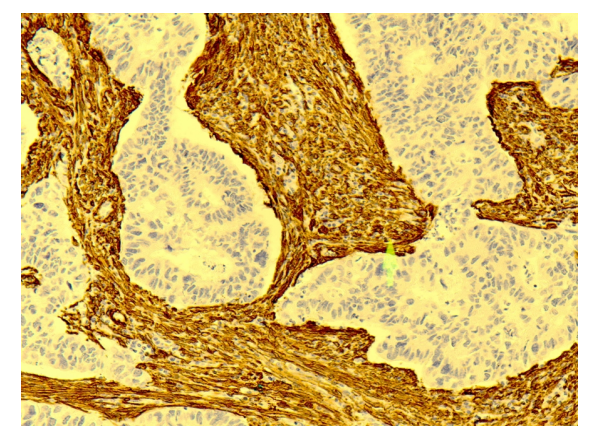

Figure 3. Left panel: This photo shows an endometrial polyp with benign looking glands surrounded by stroma. Neither stroma nor do glandular tissue do express actin, however, microvessel staining is shown in capillaries which are dark brown (20× magnification). Right panel: This micro photo shows endometrial cancer tissue stained with actin. The negatively stained malignant glandular tissue is surrounded by stroma stained dark brown demonstrating strong expression of actin (40× magnification).

Table 3. Differences of immunohistochemical score for expression of CD31, CD34 and actin in microvessels in polyps and cancers.

\begin{tabular}{lccc}
\hline (a) Expression of CD31 & & & \\
Localization of staining & Benign polyps Mean $\pm \mathrm{SD}(\mathrm{N}=15)$ & Cancer Mean $\pm \mathrm{SD}(\mathrm{N}=16)$ & p-value \\
\hline Arterioles & $31.3 \pm 30.2$ & $58.8 \pm 20.6$ & 0.006 \\
Venyles & $44.7 \pm 22.3$ & $60.6 \pm 18.4$ & 0.038 \\
Capillaries & $48.7 \pm 23.6$ & $71.9 \pm 13.3$ & 0.002 \\
\hline (b) Expression of CD34 & & & \\
Localization of staining & Benign polyps Mean $\pm \mathrm{SD}(\mathrm{N}=15)$ & Cancer Mean $\pm \mathrm{SD}(\mathrm{N}=16)$ & p-value \\
\hline Arterioles & $80.0 \pm 8.5$ & $68.3 \pm 24.0$ & 0.087 \\
Venyles & $80.0 \pm 8.5$ & $65.0 \pm 25.1$ & 0.037 \\
Capillaries & $79.3 \pm 8.8$ & $69.0 \pm 23.9$ & 0.128 \\
\hline (c) Expression of actin & & & \\
Localization of staining & Benign polyps Mean $\pm \mathrm{SD}(\mathrm{N}=15)$ & Cancer Mean $\pm \mathrm{SD}(\mathrm{N}=16)$ & p-value \\
\hline Arterioles & $70.7 \pm 8.0$ & $72.5 \pm 6.8$ & 0.49 \\
Venyles & $70.7 \pm 8.0$ & $72.5 \pm 6.8$ & 0.34 \\
Capillaries & $21.3 \pm 20.0$ & $73.8 \pm 7.2$ & $<0.0001$ \\
\hline
\end{tabular}


Table 4. H-score for VEGF, VEGFB, VEGFR2, CD 34 and actin in glands and stroma in polyps and cancers, respectively.

(a) Expression of VEGF in cytoplasm. Cell membrane was unstained in polyps as well as in cancers.

\begin{tabular}{cccc} 
Localization of staining & Benign polyps Mean $\pm \mathrm{SD}(\mathrm{N}=15)$ & Cancer Mean $\pm \mathrm{SD}(\mathrm{N}=16)$ & $\mathrm{p}$-value \\
\hline Glandular cells & $184.7 \pm 66.8$ & $132.5 \pm 80.7$ & 0.167 \\
Stromal cells & $20.6 \pm 33.4$ & $25.0 \pm 36.3$ & 0.921 \\
\hline
\end{tabular}

(b) Expression of VEGFB in cytoplasm (CP) and cell membrane (CM) of glandular cells and cytoplasm (CP) of stromal cells. Cell membrane was unstained in polyps.

\begin{tabular}{cccc} 
Localization of staining & Benign polyps Mean $\pm \mathrm{SD}(\mathrm{N}=15)$ & Cancer Mean $\pm \mathrm{SD}(\mathrm{N}=16)$ & p-value \\
\hline Glands/CP & $53.6 \pm 41.8$ & $63.1 \pm 48.0$ & 0.525 \\
Glands/CM & $0.93 \pm 0.47$ & $0.13 \pm 0.34$ & 0.0003 \\
Stroma/CP & $32.1 \pm 30.7$ & $2.5 \pm 10.0$ & 0.012 \\
\hline
\end{tabular}

(c) Expression of VEGFR2 in cytoplasm (CP) and cell membrane (CM) of glandular cells and cytoplasm (CP) of stromal cells. Cell membrane was unstained in polyps.

\begin{tabular}{cccc} 
Localization of staining & Benign polyps Mean $\pm \mathrm{SD}(\mathrm{N}=15)$ & Cancer Mean $\pm \mathrm{SD}(\mathrm{N}=16)$ & $\mathrm{p}$-value \\
\hline Glands/CP & $2.3 \pm 5.6$ & $25.6 \pm 31.4$ & 0.0137 \\
Glands/CM & $0.47 \pm 0.52$ & $0.13 \pm 0.34$ & 0.109 \\
Stroma/CP & $2.7 \pm 7.0$ & $11.9 \pm 36.4$ & 0.625 \\
\hline
\end{tabular}

(d) Expression of CD34 in cytoplasm. Cell membrane was unstained in polyps as well as in cancers.

\begin{tabular}{cccc} 
Localization of staining & Benign polyps Mean $\pm \mathrm{SD}(\mathrm{N}=15)$ & Cancer Mean $\pm \mathrm{SD}(\mathrm{N}=16)$ & $\mathrm{p}$-value \\
\hline Glandular cells & 0 & 0 & - \\
Stromal cells & $93.3 \pm 90.1$ & $12.5 \pm 27.2$ & 0.0122 \\
\hline
\end{tabular}

(e) Expression of actin in cytoplasm. Cell membrane was unstained in polyps as well as in cancers.

\begin{tabular}{cccc} 
Localization of staining & Benign polyps Mean $\pm \mathrm{SD}(\mathrm{N}=15)$ & Cancer Mean $\pm \mathrm{SD}(\mathrm{N}=16)$ & $\mathrm{p}$-value \\
\hline Glandular cells & 0 & 0 & - \\
Stromal cells & $54.3 \pm 83.1$ & $217 \pm 48.4$ & 0.0002 \\
\hline
\end{tabular}

\section{DISCUSSION}

As far as we know, this is the first report studying angiogenic markers in histopathological material comparing benign polyps and cancers. As endometrial cancer is now the most frequent gynaecological malignancy in the Western world and the incidence is constantly increasing, potential biological markers for cancer development to select high risk cases for surgical treatment would be of importance in daily routine. In former studies other risk indicators of malignant development in polyps like age, menopausal status, polyp diameter, and hypertension have been evaluated $[1,21-23]$. Thus, in a recent study polyp diameter exceeding $18 \mathrm{~mm}$ was significantly associated to an abnormal histology [22]. Also Rahimi and co-workers concluded that postmenopausal women with larger polyps had a 3.6-fold higher likelihood of atypia [23]. However, such indicators have limited value as they do not exclude malignancy in smaller lesion and more exact diagnostic guidelines are important to determine optimal and individualized therapy.
Among the most remarkable result in the current study of angiogenic markers was the reduction in CD34 expression in stromal tissue coinciding with increased expression of stromal actin in cancers compared to polyps. Correspondingly, in a study of non invasive cervical cancer a dense network of $\mathrm{CD} 34$ positive stromal fibrocytes was observed, whereas, the stroma of invasive carcinoma was virtually free of this cell population [24]. Early stromal invasive squamous carcinoma was also characterized by a focal loss of expression of CD34 fibrocytes. In normal cervical stroma actin positive myofibroblasts were not seen [24]. Similar results were confirmed in another study from premalignant and malignant disease of the uterine cervix demonstrating that the disappearance of CD34-positive stromal cells and appearance of actin positive stromal myofibroblasts were associated with malignant transformation [25]. Also in studies from breast pathology it has been shown that reduction in CD34 expression and concurrent increase in actin may be considered as helpful tools in distinguishing benign breast lesions (e.g., sclerosing adenosis) from inva- 
sive breast cancer [26].

Increased single expression of actin has also been considered in diagnostics of breast cancer and in a recent study from Yamashita and co-workers the authors conclude that stromal myofibroblasts stained immunohistochemically by alpha smooth muscle actin represent an important prognostic factor for invasive growth that may be translated into a poor clinical prognosis for patients with invasive breast cancer [27].

Other studies have also asserted that the stromal reaction in different carcinomas may be of major importance and CD34-positive stromal cells may play a significant role in the host response to tissue damage showing immune-mediated host defence against invading tumour cells $[24,25]$. In a recent study Nakayama and co-workers described that loss of CD34 expression in stroma was associated with invasive carcinoma and in part, accompanied by a gain of actin positive myofibroblasts in the stroma of colorectal cancer cells [28]. Most of the stromal cells in the normal colorectal submucosa, muscularis propria, subserosa, and perirectal tissue were positive for CD34. In contrast, the peritumoral inflammatory tissue and the tumor stroma had no CD34 positive stromal cells [28]. Although further investigations are essential, expression of CD34 and actin in stromal tissue within endometrial polyps with different malignant potential may become important future markers for evaluation of malignant potential and cancer development.

Another remarkable finding in the current study was the significantly increased expression of the pan-endothelial marker CD31 in arterioles, capillaries and venyles in endometrial cancers compared to polyps. Former studies investigating the significance of CD31 expression as a prognostic marker in endometrial polyps have never been performed. In a recent retrospective immunohistochemical study evaluating expression of CD31 and CD105 (endoglin) in pancreatic cancers with different outcome, the authors concluded that angiogenesis-associated molecules like CD31 and CD105 might be useful tools as prognostic markers in pancreatic cancers [29]. On the other hand, for the second endothelial marker, CD34, the expression of CD34 was shown to be reduced in microvessels (venyles) in cancers compared to polyps in the present study.

In the present study VEGFR2 expression showed an increased $\mathrm{H}$-score in cytoplasm of glandular tissue in the endometrial cancers compared to polyps. Although no significant difference between the two groups was asserted, VEGF was substantially expressed in both groups with high H-score levels. In a recent study Koukourakis and co-workers demonstrated that serum levels of VEGF were increased in patients with breast and gynecological malignancies but also in certain benign conditions, including cases of fibrocystic disease of the breast and in simple endometrial hyperplasia $[23,30]$. They also found that expression of phosphorylated VEGFR2/KDR receptors was higher in breast, endometrial, and ovarian cancer in patients with high VEGF serum levels reaching a level of statistical significance when all malignancies were combined. Further, a stimulatory effect of serum VEGF on the VEGF pathway contributing to tumour progression was indicated $[23,30]$. In our study serum levels of VEGF was never estimated although epithelial expression was outstanding with high $\mathrm{H}$-score levels in both groups. Thus, increased H-score for VEGFR2 in malignant epithelium, as demonstrated in our results, may indicate increased stimulatory effects of VEGF in pathological angiogenesis and VEGFR2 might work as a marker for malignant transformation independent of VEGF [31].

Measurement of micro vessel density was also performed in areas of most active neo-vascularisation in polyps as well as in cancers. However, no significant difference between the two groups could be detected. No other studies exist in the literature investigating micro vessel density as prognostic factor for malignant development in endometrial polyps.

The present study strongly indicates that angiogenesis is different in benign endometrial polyps and in endometrial cancers. Thus, immunohistochemical expression of specific angiogenic markers may be of great importance as prognostic factors in the routine diagnostics of this lesion. Particularly the ratio between stromal expression of CD34 and actin might be of interest to select polyps with increased malignant potential. To obtain more profound knowledge within this area larger series of endometrial polyps with long-term follow is required. Such studies are in progress.

\section{ACKNOWLEDGEMENTS}

We want to thank Tove Noren for excellent immunohistochemical work.

\section{REFERENCES}

[1] Anastasiadis, P.G., Koutlaki, N.G., Skaphida, P.G., Galazios, G.C., Tsikouras, P.N. and Liberis, V.A. (2000) Endometrial polyps: Prevalence, detection, and malignant potential in women with abnormal uterine bleeding. European Journal of Gynaecological Oncology, 21, 180-183.

[2] Clevenger-Hoeft, M., Syrop, C.H., Stovall, D.W. and Van Voorhis, B.J. (1999) Sonohysterography in premenopausal women with and without abnormal bleeding. $\mathrm{Ob}$ stetrics \& Gynecology, 94, 516-520. doi:10.1016/S0029-7844(99)00345-2

[3] Cohen, I. (2004) Endometrial pathologies associated with postmenopausal tamoxifen treatment. Gynecologic Oncology, 94, 256-266. doi:10.1016/j.ygyno.2004.03.048 
[4] Van Bogaert, L.J. (1988) Clinicopathologic findings in endometrial polyps. Obstetrics \& Gynecology, 71, 771773.

[5] Lieng, M., Qvigstad, E., Sandvik, L., Jorgensen, H., Langebrekke, A. and Istre, O. (2007) Hysteroscopic resection of symptomatic and asymptomatic endometrial polyps. Journal of Minimally Invasive Gynecology, 14, 189-194. doi:10.1016/j.jmig.2006.09.018

[6] Mutter, G.L., Nucci, M.R. and Robboy, S.J. (2010) Endometritis, polyps and miscellaneous changes. Curchill Livingstone Elsevier, Edinburgh, 343-366.

[7] Bakour, S.H., Khan, K.S. and Gupta, J.K. (2000) The risk of premalignant and malignant pathology in endometrial polyps. Acta Obstetricia et Gynecologica Scandinavica, 79, 317-320. doi:10.1080/j.1600-0412.2000.079004317.x

[8] Deligdisch, L., Kalir, T., Cohen, C.J., De, L.M., Le, B.G. and Penault-Llorca, F. (2000) Endometrial histopathology in 700 patients treated with tamoxifen for breast cancer. Gynecologic Oncology, 78, 181-186. doi:10.1006/gyno.2000.5859

[9] Pettersson, B., Adami, H.O., Lindgren, A. and Hesselius, I. (1985) Endometrial polyps and hyperplasia as risk factors for endometrial carcinoma. A case-control study of curettage specimens. Acta Obstetricia et Gynecologica Scandinavica, 64, 653-659. doi: $10.3109 / 00016348509158208$

[10] Baak, J.P., Wisse-Brekelmans, E.C., Fleege, J.C., Van der Putten, H.W. and Bezemer, P.D. (1992) Assessment of the risk on endometrial cancer in hyperplasia, by means of morphological and morphometrical features. Pathology Research and Practice, 188, 856-859. doi:10.1016/S0344-0338(11)80244-X

[11] Horn, L.C., Schnurrbusch, U., Bilek, K., Hentschel, B. and Einenkel, J. (2004) Risk of progression in complex and atypical endometrial hyperplasia: Clinicopathologic analysis in cases with and without progestogen treatment. International Journal of Gynecological Cancer, 14, 348353. doi:10.1111/j.1048-891x.2004.014220.x

[12] Kurman, R.J., Kaminski, P.F. and Norris, H.J. (1985) The behavior of endometrial hyperplasia. A long-term study of "untreated" hyperplasia in 170 patients. Cancer, 56, 403-412.

doi:10.1002/1097-0142(19850715)56:2<403::AID-CNC R2820560233>3.0.CO;2-X

[13] Pennant, S., Manek, S. and Kehoe, S. (2008) Endometrial atypical hyperplasia and subsequent diagnosis of endometrial cancer: A retrospective audit and literature review. Journal of Obstetrics \& Gynaecology, 28, 632-633. doi:10.1080/01443610802355817

[14] Lieng, M., Qvigstad, E., Dahl, G.F. and Istre, O. (2008) Flow differences between endometrial polyps and cancer: A prospective study using intravenous contrast-enhanced transvaginal color flow Doppler and three-dimensional power Doppler ultrasound. Ultrasound in Obstetrics \& Gynecology, 32, 935-940. doi:10.1002/uog.6267

[15] Mints, M., Blomgren, B., Falconer, C. and Palmblad, J. (2002) Expression of the vascular endothelial growth factor (VEGF) family in human endometrial blood vessels. Scandinavian Journal of Clinical and Laboratory
Investigation, 62, 167-175. doi: $10.1080 / 003655102317475425$

[16] Erdem, O., Erdem, M., Erdem, A., Memis, L. and Akyol, G. (2007) Expression of vascular endothelial growth factor and assessment of microvascular density with CD 34 and endoglin in proliferative endometrium, endometrial hyperplasia, and endometrial carcinoma. International Journal of Gynecological Cancer, 17, 1327-1332. doi:10.1111/j.1525-1438.2007.00942.x

[17] Kaku, T., Yoshikawa, H., Tsuda, H., Sakamoto, A., Fukunaga, M., Kuwabara, Y., Hataeg, M., Kodama, S., Kuzuya, K., Sato, S., Nishimura, T., Hiura, M., Nakano, H., Iwasaka, T., Miyazaki, K. and Kamura, T. (2001) Conservative therapy for adenocarcinoma and atypical endometrial hyperplasia of the endometrium in young women: Central pathologic review and treatment outcome. Cancer Letters, 167, 39-48. doi:10.1016/S0304-3835(01)00462-1

[18] Guset, G., Costi, S., Lazar, E., Dema, A., Cornianu, M., Vernic, C. and Paiusan, L. (2010) Expression of vascular endothelial growth factor (VEGF) and assessment of microvascular density with CD34 as prognostic markers for endometrial carcinoma. Romanian Journal of Morphology and Embryology, 51, 677-682.

[19] Huang, A., Pettigrew, N.M. and Watson, P.H. (1996) Immunohistochemical assay for oestrogen receptors in paraffin wax sections of breast carcinoma using a new monoclonal antibody. Journal of Pathology, 180, 223227. doi:10.1002/(SICI)1096-9896(199610)180:2<223::AID-P ATH635>3.0.CO;2-H

[20] Vermeulen, P.B., Gasparini, G., Fox, S.B., Toi, M., Martin, L., McCulloch, P., Pezzella, F., Viale, G., Weidner, N., Harris, A.L. and Dirix, L.Y. (1996) Quantification of angiogenesis in solid human tumours: An international consensus on the methodology and criteria of evaluation. European Journal of Cancer, 32A, 2474-2484. doi:10.1016/S0959-8049(96)00379-6

[21] Savelli, L., De, I.P., Santini, D., Rosati, F., Ghi, T., Pignotti, E. and Bovicelli, L. (2003) Histopathologic features and risk factors for benignity, hyperplasia, and cancer in endometrial polyps. American Journal of Obstetrics \& Gynecology, 188, 927-931. doi:10.1067/mob.2003.247

[22] Ferrazzi, E., Zupi, E., Leone, F.P., Savelli, L., Omodei, U., Moscarini, M., Barbieri, M., Cammareri, G., Capobianco, G., Cicinelli, E., Coccia, M.E., Donarini, G., Fiore, S., Litta, P., Sideri, M., Solima, E., Spazzini, D., Testa, A.C. and Vignali, M. (2009) How often are endometrial polyps malignant in asymptomatic postmenopausal women? A multicenter study. American Journal of Obstetrics \& Gynecology, 200, 235-236. doi:10.1016/j.ajog.2008.09.876

[23] Rahimi, S., Marani, C., Renzi, C., Natale, M.E., Giovannini, P. and Zeloni, R. (2009) Endometrial polyps and the risk of atypical hyperplasia on biopsies of unremarkable endometrium: A study on 694 patients with benign endometrial polyps. International Journal of Gynecological Pathology, 28, 522-528. doi:10.1097/PGP.0b013e3181a42228

[24] Barth, P.J., Ramaswamy, A. and Moll, R. (2002) CD34(+) 
fibrocytes in normal cervical stroma, cervical intraepithelial neoplasia III, and invasive squamous cell carcinoma of the cervix uteri. Virchows Arch, 441, 564-568. doi:10.1007/s00428-002-0713-y

[25] Li, Q., Huang, W. and Zhou, X. (2009) Expression of CD34, alpha-smooth muscle actin and transforming growth factor-betal in squamous intraepithelial lesions and squamous cell carcinoma of the cervix. Journal of International Medical Research, 37, 446-454.

[26] Barth, P.J., Ebrahimsade, S., Ramaswamy, A. and Moll, R. (2002) CD34+ fibrocytes in invasive ductal carcinoma, ductal carcinoma in situ, and benign breast lesions. Virchows Arch, 440, 298-303. doi:10.1007/s004280100530

[27] Yamashita, M., Ogawa, T., Zhang, X., Hanamura, N., Kashikura, Y., Takamura, M., Yoneda, M. and Shiraishi, T. (2010) Role of stromal myofibroblasts in invasive breast cancer: Stromal expression of alpha-smooth muscle actin correlates with worse clinical outcome. Breast Cancer.

[28] Nakayama, H., Enzan, H., Miyazaki, E., Kuroda, N.,
Naruse, K. and Hiroi, M. (2000) Differential expression of CD34 in normal colorectal tissue, peritumoral inflammatory tissue, and tumour stroma. Journal of Clinical Pathology, 53, 626-629. doi:10.1136/jcp.53.8.626

[29] Tachezy, M., Reichelt, U., Melenberg, T., Gebauer, F., Izbicki, J.R. and Kaifi, J.T. (2010) Angiogenesis index CD105 (endoglin)/CD31 (PECAM-1) as a predictive factor for invasion and proliferation in intraductal papillary mucinous neoplasm (IPMN) of the pancreas. Histology and Histopathology, 25, 1239-1246.

[30] Koukourakis, M.I., Limberis, V., Tentes, I., Kontomanolis, E., Kortsaris, A., Sivridis, E. and Giatromanolaki, A. (2011) Serum VEGF levels and tissue activation of VEGFR2/KDR receptors in patients with breast and gynecologic cancer. Cytokine, 53, 370-375. doi:10.1016/j.cyto.2010.12.007

[31] Shibuya, M. (2006) Differential roles of vascular endothelial growth factor receptor-1 and receptor-2 in angiogenesis. Journal of Biochemistry and Molecular Biology, 39, 469-478. doi:10.5483/BMBRep.2006.39.5.469 